\title{
Prevalence of older adults' abuse and neglect in Portugal: an overview
}

\author{
Ana João Santos, José Ferreira-Alves and Bridget Penhale
}

\author{
Ana João Santos is \\ Researcher in the \\ School of Psychology, \\ University of Minho, \\ Braga, Portugal. \\ José Ferreira-Alves is an \\ Assistant Professor in the \\ School of Psychology, \\ University of Minho, \\ Braga, Portugal. \\ Bridget Penhale is a Reader \\ in Mental Health of Older \\ People in the School of \\ Nursing and Midwifery, \\ Faculty of Health, \\ University of East Anglia, \\ Norwich, UK.
}

\begin{abstract}
Purpose - The purpose of this paper is to identify, describe and compare the studies of the prevalence of abuse and neglect of older adults developed in Portugal.

Design/methodology/approach - A retrospective bibliographic search of seven descriptors in English and Portuguese, of academic and professional papers and university institutional repositories was performed.

Findings - Of the nine studies selected, seven consisted of grey literature - research developed within the course of academic post-graduate studies. The studies were conducted on a small scale, more often than not, through a non-probabilistic convenience sampling method. From the nine studies, two instruments prevailed: the Questions to Elicit Elder Abuse aimed at older adults and the Caregiver Abuse Screen aimed at caregivers. Community-dwelling older adults self-reported a higher prevalence of abuse (between 66.7 and 86.7 per cent) than care professionals working with older adults suffering from dementia (between 26.7 and 47.4 per cent). Emotional abuse and neglect were the first and second most prevalent forms of abuse, followed by financial abuse, whereas physical abuse was the least prevalent type of abuse encountered. A poorer perception of health, not making/receiving visits and residing in an urban area were the more consistent variables associated with abuse of older adults.

Originality/value - Overall, this paper provides a first consideration to the prevalence rates of older adult abuse and neglect from research studies in Portugal. The revised design studies and screening methods employed can help researchers improve future study design and move from the description to a more theoretically oriented research. Furthermore, it can help practitioners learn screening methods and discover the findings associated with abuse.
\end{abstract}

Keywords Prevalence, Older adult abuse and neglect, Elder mistreatment, Elder abuse screening, Elderly people, Portugal

Paper type Literature review

\section{Introduction}

The abuse and neglect of older adults is an important social phenomenon that only recently, mainly for the last three decades has been brought into the attention of science, professional practice, public opinion and authorities (Lachs and Pillemer, 2004). Nowadays, it is viewed as a public health problem, particularly since older adults' abuse has been associated with higher rates of morbidity (Kleinschmidt, 1997). Notwithstanding this increase of interest, the field of abuse of older adults still remains the least acknowledged of the types of human violence (O'Connor and Rowe, 2005).

The full dimension of older adult abuse and neglect in Portugal is still unclear and, considering the rapid aging of the country, the need to obtain a more accurate picture is affirmed: whilst in 1991, the population of over 65 year olds represented 14 per cent in 2006 this percentage reached 17.25 per cent and is projected to continue to increase in future (Instituto Nacional de Estatística (INE), 2008). Furthermore, the increase in life expectancy and of older adults over 85 years old stands for a probable higher number of dependent older adults (José et al., 2002), more susceptible to abuse and neglect. 
Additionally, the population of older adults in Portugal presents features that may increase the potential vulnerability of this age group, when compared to other European countries. In 2008, some 22 per cent of Portuguese older adults were at risk of poverty, with their income being below the poverty threshold[1] (Eurostat News Release, 2010), situating it above the European mean at 19 per cent. The older adults' population presents low levels of education. According to the International Standard Classification of Education (ISCED)[2], by 2001, 55.1 per cent of the older adults were situated at level 0 , which is equivalent to pre-school or no schooling (INE, 2001).

In terms of policy, it can be stated that although several measures have been developing aimed at the improvement of quality life of this population, social provision seems unable to respond appropriately to the needs of older adults and, for instance, in terms of equipment and services towards older adults (residential facilities, domiciliary support services and so forth.) the demands still exceed the offers. By 2000, the numbers on waiting lists was equivalent to a third of the total capacity of the services and equipment offered (José et al., 2002).

Furthermore, Portuguese policy has not been specifically developed at older adults' abuse and neglect, but within the broad umbrella of domestic violence and with "primordial object being the intervention against violence on women" (III Plan Against Domestic Violence, Ministers Council Resolution No. 51/07[3]).

Overall, a total of two governmental and one not for profit victim support association projects have been developed in response to older adult abuse and neglect, comprising a Senior Citizen Helpline created in 1999 by the Portuguese Ombudsman; a work group developed in 2008 for the prevention of violence against older adults, within the General Direction of Health of the Health Ministry and the "Títono" project developed by the Portuguese Association of Victims Support encompassing the development of specific training programmes and the production of manuals for professionals responding to older adult victims of crime and domestic violence.

Older Portuguese adults may be more vulnerable, in comparison with the majority of other European countries, given the risks of poverty, social exclusion and isolation, which together with the lack of policies directed at abuse and neglect and this, may contribute to differences in prevalence rates of the phenomenon.

\section{Methods}

A retrospective bibliographic search was conducted on studies of prevalence of abuse and neglect in older adults in Portugal.

The search was carried out in the online knowledge library (b-on) (www.b-on.pt/), which is a national portal providing access to national research and higher education institutions to full texts from over 16,750 scientific international publications from several publishers and databases.

Seven descriptors were used, namely:

1. elder abuse;

2. elder abuse and neglect;

3. older adults' abuse;

4. elder maltreatment;

5. domestic violence;

6. family violence; and

7. prevalence.

For each of the descriptors the Boolean search option was employed (e.g. elder abuse or elder abuse and neglect and prevalence). Both English and Portuguese languages were employed in the international and national databases. 
In relation to the criteria selected, all studies assessing the prevalence of older adult abuse and neglect conducted in Portugal, either at a regional or national level were included and, therefore, prevalence studies conducted in other countries were not. Additionally, studies aiming at conjugal violence of younger adults or child mistreatment were excluded.

Of the several publishers and databases, a total of 51 abstracts were retrieved from Academic Search complete, EBSCO, MEDLINE, ScienceDirect, Psycharticles and Psycholnfo. A total of five abstracts were retrieved targeting older adult abuse and neglect by employing the key words in the Portuguese language. Only two of these were included, given that the others did not constitute research on prevalence.

The search with the English key-words provided a total of 46 abstracts regarding studies of the abuse and neglect of older adults, which encompassed national or regional and random or convenience samples, institutional or community settings and diverse target groups. However, none of these studies were included, since none had been conducted in Portugal. Given the low number of relevant studies encountered, a new search was conducted in repositories of Portuguese universities and national key-researchers were contacted to provide studies about the prevalence on older adults' abuse and neglect and seven additional studies were obtained by these means.

\section{Results}

The research developed in Portugal on older adult abuse and neglect is quite recent (all research dates between 2005 and 2010) and has, for the most part, evolved within the course of academic proofs at masters level or other post-graduate studies.

A total of nine studies were selected to be included in the review. Two consisted of published articles: one published in a German book (Ferreira-Alves et al., 2010), whose author provided a published Portuguese version and the other published in a Portuguese journal (Ferreira-Alves and Sousa, 2005), whose data were completed from a more in-depth unpublished manuscript of the same study (Ferreira-Alves et al., 2009). Seven of the studies encompassed grey literature: one unpublished article (Afonso et al., 2009) one oral presentation from a meeting (Borralho et al., 2010); three college monographs (Chaves et al., 2009; Fernandes and Dionísio, 2009; Paloteia, 2008) and two Masters Theses (Silva, 2009; Vergueiro, 2009).

The results section discusses the studies selected according to the methodologies employed; prevalence rates obtained by overall, types of abuse and the variables associated with abuse, including socio-demographic and health variables and knowledge of dementia symptoms by professional caregivers.

\section{Methodologies}

Table I displays the methodologies employed by the sampling method, participants, setting and instruments. All the studies were conducted on a small scale (only between 32 and 296 respondents were reached per research) with diversified target groups (older adults; informal caregivers; professional caregivers and technical managers and administrators[4] of residential facilities) and settings (institutional and communitarian).

The sampling method more often applied (six of the nine studies) is a non-probabilistic convenience selection of the target group (Borralho et al., 2010; Chaves et al., 2009; Fernandes and Dionísio, 2009; Ferreira-Alves and Sousa, 2005; Paloteia, 2008; Vergueiro, 2009). In three studies (Afonso et al., 2009; Ferreira-Alves et al., 2010; Silva, 2009) all cases within a particular setting were selected, consisting, therefore, of a purposive sample.

In six of the nine studies, the participants were older adults, whilst three other studies targeted staff members from residential facilities. Three studies targeted only community-dwelling older adults, sampled in a hospital emergency service during a one-week period (Borralho et al., 2010); in three day centers[5] (Ferreira-Alves and Sousa, 2005) and in several social and non-profitable institutions located in one country district (Chaves et al., 2009).

Although older adults were also targeted in three other studies, these did not only encompass those living at their private residential addresses. In Fernandes and Dionísio's (2009) study, 


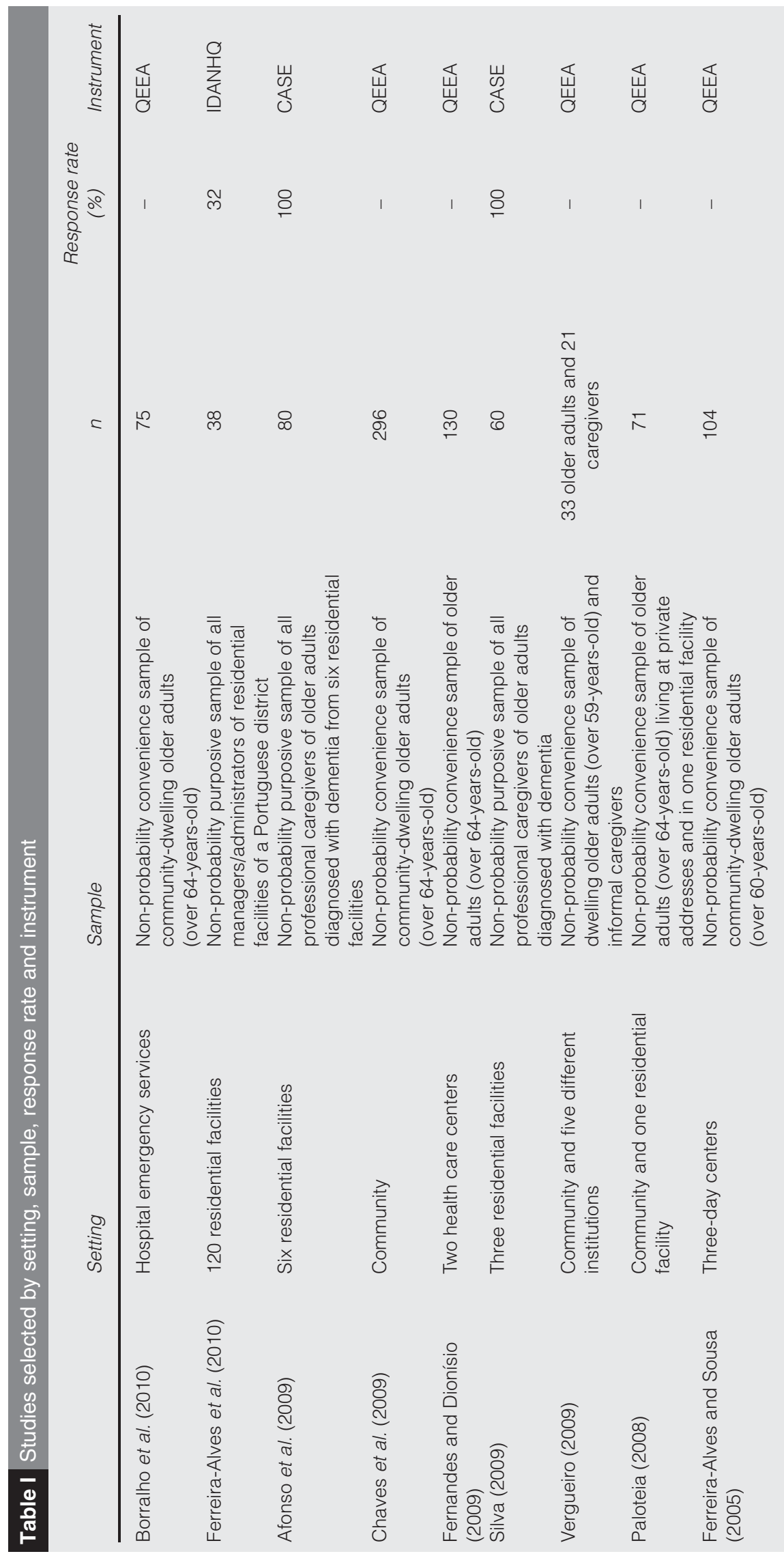


older adults attending medical and/nursing appointments were approached in three health care centers[6] during a 15-day period. Paloteia (2008) sampled both institutionalised and community-dwelling older adults in one residential facility and in the community through use of a snowballing method. Vergueiro (2009) gathered a sample of both older adults and informal caregivers in a rural community using a door-to-door method and in five institutions[7] of a city where the researcher contacted older adults and asked them if they wished to participate.

Commonly in the case of older adult respondents, the participants' inclusion criteria were the age and the non-existence of cognitive impairment. The lower age limit was established at 65 years (four out of six studies) and at 60 years and over (two studies). Cognitive status was not assessed in one study (Paloteia, 2008), while the other studies including older adults as respondents applied the following instruments directed at evaluating cognitive impairment: Short Portable Mental Status Questionnaire (Pfeiffer, 1975) and the Mini-mental State Examination (Folstein et al., 1975).

Three studies targeted professionals working in older adult residential facilities. Two studies (Afonso et al., 2009; Silva, 2009) targeted care attendants working in residential facilities of older adults diagnosed with dementia and Ferreira-Alves et al. (2010) asked technical managers and administrators of all residential facilities of the country district about reported incidents of abuse and neglect.

In relation to data collection, personal face-to-face interviews were accomplished in eight of the studies. In the ninth study, by Ferreira-Alves et al. (2010), a postal method was employed and questionnaires were sent by mail to a number of institutions.

The concept of abuse and neglect was more often than not operationalised by the Questions to Elicit Elder Abuse (QEEA), a research version partially validated by Ferreira-Alves and Sousa (2005) from the original developed by Carney et al. (2003). The QEEA is a self-reported measure of 15 closed questions divided into four parts, which are related to physical and emotional abuse, neglect and exploitation. This instrument was initially designed to be used within a clinical setting, as a screen for the possibility of abuse occurrence and also to shed some light on the understanding and management of some physical or psychological symptoms. Each item corresponds to a major group of abusive experiences that requires later assessment when it is positively signed (Carney et al., 2003). No total score is provided, since its initial purpose was only to recognize, manage and prevent elder abuse. Although no psychometric properties are available for this questionnaire and its reliability and validity has never been established for the English version (Carney et al., 2003); in relation to the Portuguese population, one study observed an internal consistency by Cronbach's alpha of 0.83 for the 15 items (Ferreira-Alves and Sousa, 2005).

The Caregiver Abuse Screen (CASE) instrument, a research version partially validated by Ferreira-Alves et al. (2007b) from the original of Reis and Nahmiash (1995) was utilised in two studies. The CASE consists of eight items, requiring "yes" or "no" answers, which are filled in by the caregiver and only concern the likelihood of abuse and neglect occurring, presenting in the original research a cut-off value of four, above which abuse is considered "likely". This value represents the median score of a group of abuser caregivers; specific scores are not provided for the different types of abuse. The authors (Reis and Nahmiash, 1995) report that CASE has validity and reliability: significantly different scores between abuser and non-abusers; Cronbach's alpha of 0.71 was reported for six out of the eight items (items 1-4, 6 and 8) and positive correlations were found between the CASE and other abuse measures, namely, the Indicators of Abuse checklist, the S-H/EAST and the Ryden verbal and physical aggression subscales. In Portugal, in one of the studies where it was applied, the internal consistency reported by Cronbach's alpha was 0.650 (Afonso et al., 2009) and the same cut-off value of the original research was used.

Only one study used the lowa Dependent Adult Abuse Nursing Home Questionnaire (IDANHQ) instrument, a research version translated by Ferreira-Alves et al. (2010) from the original of Daly and Jogerst (2005). This instrument encompasses several sections, regarding information about the technical managers/administrators' perspectives, views and 
knowledge about elder abuse and includes questions about reported incidents of abuse to the management of residential facilities. Hence, the instrument cannot be considered a direct measure of abuse and neglect of older adults.

\section{Prevalence of abuse and neglect}

Displayed in Table II is the observed prevalence within the studies selected. It should be noted that in four of the six studies using the QEEA instrument, the authors also provided the distribution of the number of indicators that were positively answered. The authors presented these results given that the design of the instrument can provide very a high percentage result, since only one positive response adds to the "overall abuse".

The range of prevalence rates varies widely, although with the exception of Ferreira-Alves et al. (2010) all studies reported relatively high values, ranging from 26.7 up to 100 per cent.

Community-dwelling older adults self-reported a prevalence of abuse that ranged between 66.7 and 86.7 per cent (Borralho et al., 2010; Chaves et al., 2009; Ferreira-Alves and Sousa, 2005; Vergueiro, 2009). In comparison, abuse was less frequently observed in institutionalised older adults. Care professionals working with older adults with dementia reported 26.7 per cent (Silva, 2009) and 47.4 per cent (Afonso et al., 2009) of responses indicative of abuse and in 38 residential facilities, only 1.2 per cent prevalence was signaled by the managers and technical directors (Ferreira-Alves et al., 2010).

Furthermore, the results reveal similarities according to the measures employed. In fact, except for Fernandes and Dioníso (2009), all studies employing the QEEA instrument presented higher prevalence values. Hence, whilst the overall prevalence of studies using the QEEA instrument ranged from 36.3 up to 100 per cent, in three of the four studies reporting the frequency by the number of indicators positively answered, a positive response to one single indicator is the commonly observed frequency (ranging from 21.3 to 33.3 per cent) (Borralho et al., 2010; Ferreira-Alves and Sousa, 2005; Vergueiro, 2009).

When it comes to types of abuse, sexual abuse was never assessed within the studies and violation of rights was only considered in one study (Ferreira-Alves et al., 2010). In addition, the studies in which the CASE instrument was used do not provide scores relating to different types of abuse.

Emotional abuse and neglect, occur, respectively, as the first and second most prevalent forms of abuse in six of the seven studies that presented scores for the different types of abuse. Only Paloteia (2008) found neglect to be the most prevalent form of abuse.

Financial abuse is the third most commonly observed type in five of the seven studies. In Fernandes and Dionísio (2009), it is the least observed type; in Ferreira-Alves et al. (2010), no financial abuse was found and in Vergueiro (2009), the informal caregivers group reported this type the second most frequently perpetrated, unlike the older adults group, for which it was the third most commonly reported type. Physical abuse was the least prevalent type of abuse encountered in four of the seven studies. This form of abuse was not found at all in Vergueiro (2009); and it was equally prevalent as violation of rights in another study (Ferreira-Alves et al., 2010) and was the second most common in Fernandes and Dionísio (2009).

\section{Variables associated with abuse}

This section examines the relation between socio-demographic and health variables and abuse, analysed in five studies and the results of two other studies assessing the relationship between the knowledge of dementia symptoms by professional careers and abuse.

Socio-demographic and health variables. Table III displays the variables examined by five studies (Borralho et al., 2010; Chaves et al., 2009; Fernandes and Dionísio, 2009; Ferreira-Alves and Sousa, 2005; Paloteia, 2008) and which were found statistically significant to abuse.

Gender, marital status, age, schooling and living arrangements were considered in all five studies, however, age and schooling were not found statistically significant in any of them and are, therefore, not displayed. 


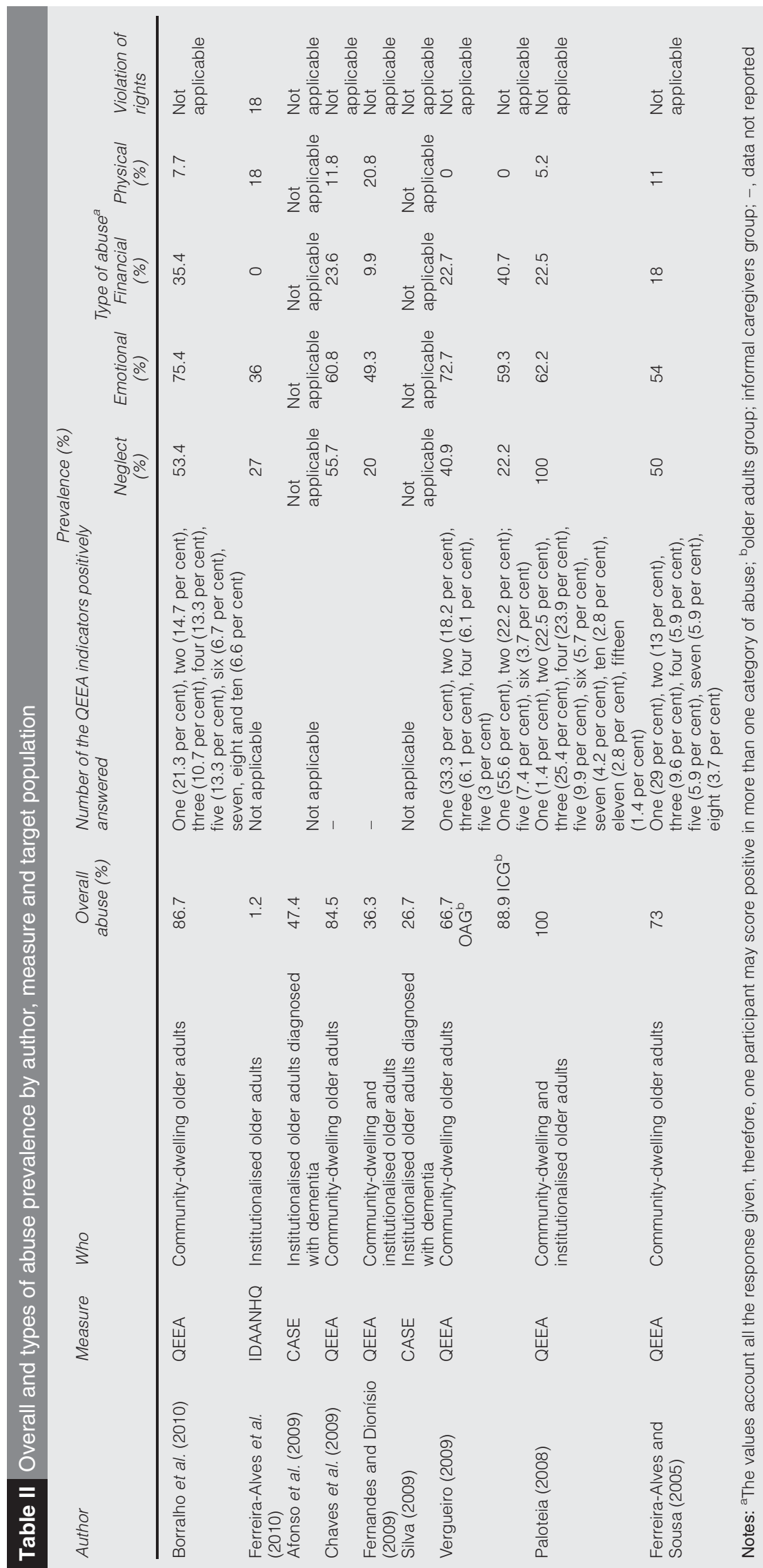




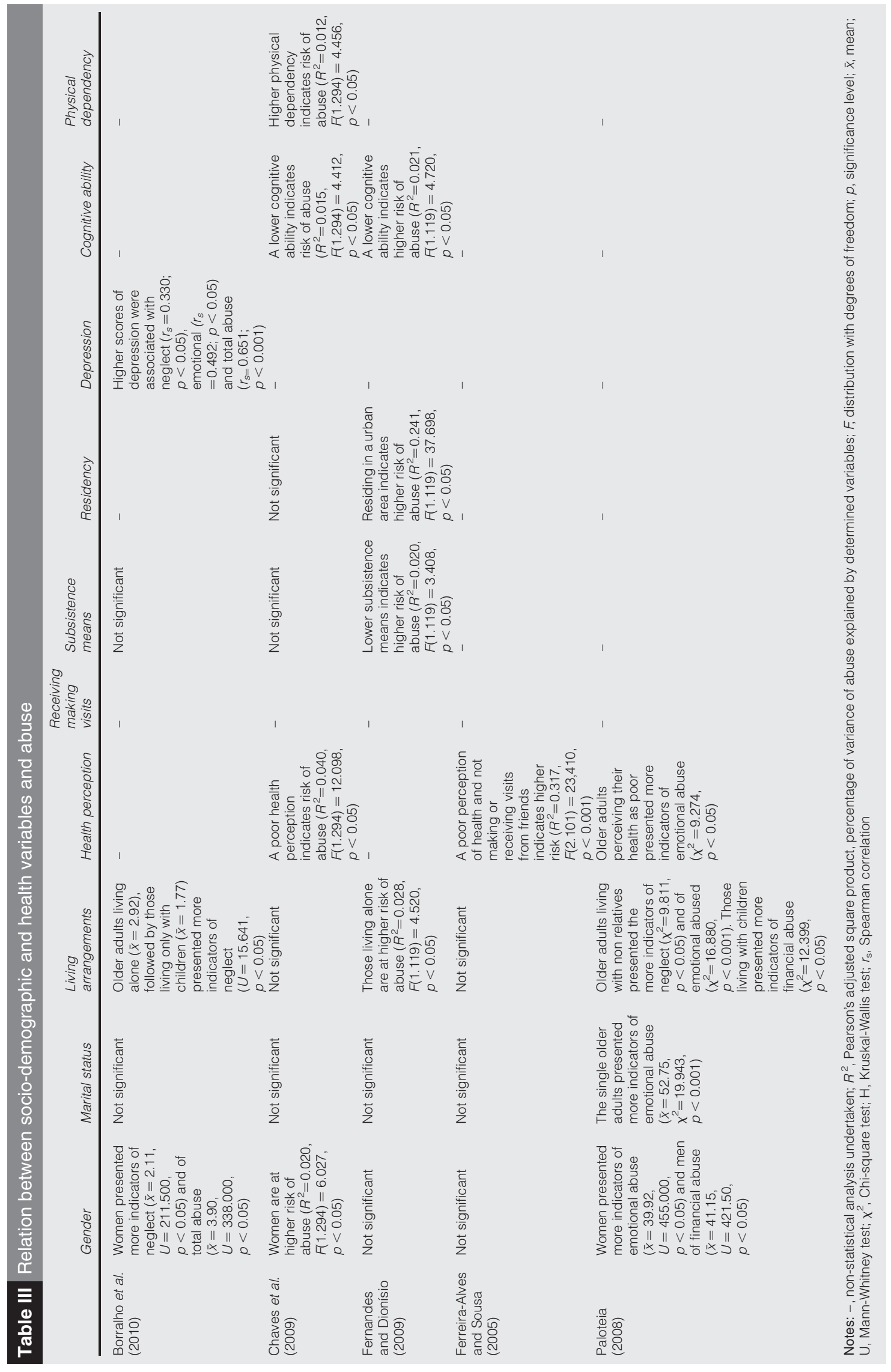


When it was considered, health perception always presented significant results (Chaves et al., 2009; Ferreira-Alves and Sousa, 2005; Paloteia, 2008), while subsistence means provided significant results in one study (Fernandes and Dionísio, 2009) and non-significant in two others (Borralho et al., 2010; Chaves et al., 2009). Of the two studies analyzing residence status (rural/urban), one presented significant results (Fernandes and Dionísio, 2009) and the other did not (Chaves et al., 2009). Three variables were only assessed in one of the five studies: receiving/making visits (Ferreira-Alves and Sousa, 2005); depression (Borralho et al., 2010) and physical dependency (Chaves et al., 2009).

Women and older adults with higher depression scores provided significantly more indicators of abuse (Borralho et al., 2010). All other variables, except for marital status were found to be predictive of abuse. Women and older adults living alone, with poorer health perception, with fewer subsistence means, residing in an urban area and presenting lower cognitive ability and higher physical dependency were at higher risk of overall abuse. Nevertheless, the explained variance of abuse was very low for most of these variables: 2 per cent for gender (Chaves et al., 2009); 2.8 per cent in living arrangements (Fernandes and Dionísio, 2009); 4 per cent for health perception (Chaves et al., 2009); 2 per cent in subsistence means (Fernandes and Dionísio, 2009); 1.5 per cent (Chaves et al., 2009) and 2.1 per cent (Fernandes and Dionísio, 2009) for cognitive ability and 1.2 per cent for physical dependency (Chaves et al., 2009).

Three variables that strongly explained abuse were the combined perception of health and receiving or making visits, which explained 31.7 per cent of prevalence variance (Ferreira-Alves and Sousa, 2005) and the location of residence, rural or urban, which explained 24.1 per cent of the variance (Fernandes and Dionísio, 2009). Overall, a poorer perception of health, not making/receiving visits and residing in an urban area were the most consistently observed risk factors. Although other variables were revealed to have low predicting values, the fact that different studies found these variables to be implicated in abuse, possibly points to their relevance, as was the case for gender and cognitive ability, indicating that women and those older adults with lower cognitive ability may also be at higher risk of abuse.

Knowledge of dementia symptoms by professional careers as predictor of abuse. Two studies of the nine reviewed examined the relationship between knowledge of symptoms by professional careers and their self-reported scores of abuse (CASE).

The authors examined the Spearman's correlation coefficient between the CASE and the measure of knowledge of the behavioural symptoms of dementia (Ferreira-Alves et al., 2007a), a self-reported questionnaire assessing the accuracy of knowledge of dementia symptoms. While Afonso et al. (2009) found no significant relationships between the knowledge of symptoms and abuse, Silva (2009) observed a significant negative correlation between those two variables $\left(r_{\mathrm{s}}=-0.263 ; p<0.05\right)$, revealing that the individuals with lower knowledge of symptoms tended to have higher scores in the CASE instrument.

\section{Discussion}

Very few published studies of prevalence of older adult abuse were found that had been conducted in Portugal. The studies retrieved by the research mostly refer to grey literature and unpublished monographs developed in the academic context.

The prevalence of abuse reported by the studies had a very wide range (1.2-100 per cent), although with exception of one study (Ferreira-Alves et al., 2010) all studies reported relatively high values, ranging from 26.7 up to 100 per cent.

The wide range of prevalence observed may result from the methodology and design of the studies. The studies were all conducted at a regional level, used non-probabilistic convenience samples with rather small sizes and only two employed instruments with reported psychometric properties. Although this may indicate some problems in the reliability of the data and caution may be advised when interpreting the results, the relevance of the results encountered in this review is given by the numbers of positive self-reports of abuse deriving from the application of the same instrument to different samples, in different settings and at different times, yet obtaining similar results. 
The lowest prevalence rate (1.2 per cent) concerned incidents reported to technical managers and directors of institutions, and is significantly less than those reported (26.7 and 47.4 per cent) by professional carers of older adults diagnosed with dementia in residential facilities. This may, on the one hand represent an actual higher incidence of abuse, given that dementia is a concomitant risk factor found in the literature (Lachs and Pillemer, 2004; Loue, 2001). Additionally, it was also observed that the accuracy of knowledge of dementia symptoms was a predictable variable for abuse by caregivers of older adults with dementia in one study and not in the other: this suggests the need to replicate this study with similar and different caregivers. The discrepancy between what the managers and directors and what the professional caregivers of institutions reported could mean less visibility and awareness of the phenomenon by the management of the residential facilities. Cooper et al. (2008) observed in their review of prevalence studies that the rates of abuse actually reported to the management of homes were low (2 per cent).

Overall, abuse was most commonly observed in community-dwelling older adults (66.7-86.7 per cent), rather than institutionalised older adults. However, in both settings, emotional abuse prevails as the most common form of abuse, followed by neglect and then, in the majority of the studies, financial abuse.

A poorer perception of health, not making/receiving visits and residing in urban areas were observed risk factors for abuse, whilst, although with somewhat less evidence, women and those older adults with reduced cognitive ability also appear to be at higher risk.

When comparing the results with international data, differences are observed in prevalence rate, which has been estimated in some Western countries between 1 and 5 per cent (Lachs and Pillemer, 2004). However, these values maybe considerably higher, as Cooper et al. (2008) revealed in a systematic review of prevalence studies, where the rate was situated between 3.2 and 27.5 per cent. Some results in Portugal do meet what has been found internationally (Cooper et al., 2008; Lachs and Pillemer, 2004; Loue, 2001): emotional abuse and neglect were indeed observed as the most prevalent forms of abuse and social isolation and reduced cognitive ability as risk factors.

In conclusion, the prevalence studies reviewed here reveal that the domain of abuse and neglect of older adults in Portugal is at an early stage in terms of research. The data from the studies, given the descriptive-correlational methodologies with selected samples living in the community and/or in residential facilities, by subjects available cannot be generalised to the Portuguese reality. With the wide range of prevalence obtained, suggesting the phenomenon being, at least, as widespread as in other Western countries; it is not possible in a canonic way to assess its dimension. In addition, this review indicates the need to further explore some theory behind the data, namely the roles of health perception, social interactions and living in urban areas, as risk factors for the occurrence of abuse. The utilization of instruments that initially were devised to screen abuse by professionals can be a promising way to do research on a large-scale not only to establish prevalence but also to test risk factors.

\section{Key-points}

- Future research focusing on more acceptable research methods, such as probability random samples and an adequate, standardised, valid and reliable abuse measure.

- Need for explicit consensus on the definition of abuse and neglect and its assessment in clinical and social practice; screening instruments for abuse should be part of the psychologist or other professional's repertoire when working with older adults.

- Increase in knowledge and skills of professional carers working with older adults and particularly in training about dementia for those working with that target group.

- Description of risk factors, such as, location of residency (urban), social isolation (not receiving/making visits), gender (women) and cognitive ability (having cognitive impairment), which practitioners should be aware of.

- Interventions to raise both professional and public sensitivity to the phenomenon 


\section{Notes}

1. The annual national at risk of poverty threshold is set at 60 per cent of the national median income per equivalent adult. The median income separates the total population into two equal parts.

2. The ISCED is an instrument developed and designed by the United Nations Educational, Scientific and Cultural Organization (2006) in the early 1970s to assemble, compile and present comparable indicators and statistics of education both within individual countries and internationally.

3. In Republics Diary, I series No. 62 from 28 March 2007.

4. Technical managers are a particular professional function of residential facilities for older adults established by Portuguese law (Ministry of Work and Social Solidarity, 1998), regarding someone with higher education (graduate level) in an appropriate academic area, preferably in social or human sciences. Administrators are responsible for controlling resources and expenditures, linked, therefore, to managing a business. In Portuguese residential facilities, this person has the same professional functions of a manager from a different institution or business.

5. The day centers are a social response providing services to satisfied basic necessities, psychological and emotional support and increment interpersonal relations; aiming at maintenance of the older adult in their social and family environment as well as the decrease of social isolation.

6. The health care centers encompassing primary health care constitute part of the national health care system and are available for all the population.

7. Psychological support service for older adults' victims of abuse and neglect of Coimbra University; a cultural association; a health center and a clinical analyses laboratory.

\section{References}

Afonso, E., Ferreira-Alves, J., Daly, J. and Martín, I. (2009), "Indicators of abuse in people with dementia living in residential facilities", working paper, School of Psychology, University of Minho, Braga, 20 December.

Borralho, O., Lima, M. and Ferreira-Alves, J. (2010), "Maus-tratos e negligência a pessoas idosas: identificação e caracterização de casos no serviço de urgência de um hospital central" ("Elder abuse and neglect: identification and characterization of cases in emergency service of a central hospital'), paper presented at the VII Simpósio Nacional de Investigação em Psicologia, Minho University, Braga.

Carney, M., Kahan, F. and Paris, B. (2003), "Elder abuse: is every bruise a sign of abuse?", The Mount Sinai Journal of Medicine, Vol. 70 No. 2, pp. 69-74.

Chaves, C., Figueiredo, A., Martins, C., Almeida, F., Almeida, J., Abrantes, P., Veiga, R. and Ferreira, S. (2009), "Indicadores de maus-tratos a pessoas idosas no distrito de Viseu" ("Elderly Indicators of abuse in the Viseu district"), Post-graduate monograph, Superior School of Health, Polytechnic Institute of Viseu, Viseu.

Cooper, C., Selwood, A. and Livingston, G. (2008), "The prevalence of elder abuse and neglect: a systematic review", Age and Ageing, Vol. 37 No. 2, pp. 151-60.

Daly, J. and Jogerst, G. (2005), "Association of knowledge of adult protective services legislation with rates of reporting of abuse in lowa nursing homes", Journal of the American Medical Directors Association, Vol. 6 No. 2, pp. 113-20.

Eurostat News Release (2010), Living Conditions in 2008: 17\% of EU27 Population at Risk of Poverty, Eurostat Press Office, London, available at: http://ec.europa.eu/eurostat (accessed 13 October 2010).

Fernandes, C. and Dionísio, R. (2009), "Violência na pessoa idosa" ("Violence on older adults"), Post-graduate monograph, Superior School of Nursing, Coimbra University, Coimbra.

Ferreira-Alves, J. and Sousa, M. (2005), "Indicadores de maus-tratos a pessoas idosas na cidade de Braga: estudo preliminar" ("Indicators of mistreatment in older adults in the city of Braga: preliminary study"), Sociologia, Vol. 15, pp. 303-13.

Ferreira-Alves, J., Afonso, E. and Martín, I. (2007a), "The assessment scale of caregiving of people with dementia in residential homes: adaptation of the 'assessment scale of informal caregiving' to residential facilities setting", unpublished manuscript, School of Psychology, University of Minho, Braga. 
Ferreira-Alves, J., Afonso, E. and Silva, M. (2007b), "The caregiver abuse screen: CASE trial version adaptation", unpublished manuscript, School of Psychology, University of Minho, Braga.

Ferreira-Alves, J., Daly, J., Sousa, M., Ferreira, M. and Jorgest, G. (2009), "Indicators of domestic elder mistreatment: a study in Portugal day care centers", working paper, School of Psychology, University of Minho, Braga, 8 October.

Ferreira-Alves, J., Soares, C., Daly, J. and Guimarães, P. (2010), "Rechtliche und psychologische ansichten zu gewalt gegen alte menschen: die perspektive von seniorenheim direkton" ("Judicial and psychological views of elder abuse: the perspective of directors of residential facilities"), in Greuel, L. and Hartmann, A. (Eds), Gewalt und vernachlässigung gegenüber alten menchen, Verlag für Polizeiwissenschaft, Frankfurt, pp. 130-41.

Folstein, M., Folstein, S. and McHugh, P. (1975), "Mini-mental state: a practical method for grading the cognitive state of patients for the clinician", Journal of Psychiatric Research, Vol. 12 No. 3, pp. 189-98.

INE (2001), Censos 2001: resultados definitivos. XIV recenseamento geral da população, IV recenseamento geral da habitação (Census 2001: Definitive Results. XIV General Population Census, IV General Housing Census), Instituto Nacional de Estatística, Lisboa.

INE (2008), O país em números. Informação estatística de 1991 a 2006 (The Country in Numbers: Statistical Information from 1991 to 2006, National Institute of Statistics), Instituto Nacional de Estatística, Lisboa.

José, J.S., Wall, K. and Correia, S.V. (2002), Trabalhar e cuidar de um idoso dependente: problemas e soluções (Working and Caring for a Dependent Elderly Person: Problems and Solutions), Instituto de Ciências Sociais, Universidade de Lisboa, Lisboa.

Kleinschmidt, K.C. (1997), "Elder abuse: a review", Annual Emergency Medicine, Vol. 30 No. 4, pp. 463-72.

Lachs, M.S. and Pillemer, K. (2004), "Elder abuse", Seminar, Vol. 364 No. 2, pp. 1263-72.

Loue, S. (2001), "Elder abuse and neglect in medicine and law: the need for reform", The Journal of Legal Medicine, Vol. 22, pp. 159-209.

O'Connor, K. and Rowe, J. (2005), "Elder abuse", Reviews in Clinical Gerontology, Vol. 15, pp. 47-54.

Paloteia, A. (2008), "Abusos na terceira idade - Um estudo sobre a auto-percepção de maus-tratos nos idosos" ("Abuse of older adults: study on the self-perception of mistreatment"), Post-graduate monograph, Superior Institute of Intercultural and Transdisciplinary Studies, Viseu.

Pfeiffer, E. (1975), "A short portable mental status questionnaire for the assessment of organic brain deficit in elderly patients", Journal of American Geriatrics Society, Vol. 23, pp. 433-41.

Reis, M. and Nahmiash, D. (1995), "Validation of the caregiver abuse screen (CASE)", Canadian Journal on Aging, Vol. 14, pp. 45-60.

Silva, A. (2009), "Conhecimento de sintomas de demência e relatos de perpetração de abuso em cuidadores" ("Knowledge of dementia symptoms and self-report of abuse by caregivers"), Master's thesis, Catholic University of Portugal, Braga.

Vergueiro, M. (2009), "O ageism e os maus-tratos contra a pessoa idosa (Ageism and mistreatment against older adults)", Master's thesis, Coimbra University, Coimbra.

\section{Further reading}

Goll, M. (2010), Population and Social Conditions: Agriculture and Fisheries, Eurostat Statistics in Focus, European Union, Brussels.

Hoff, A. (2008), Tackling Poverty and Social Exclusion of Older People: Lessons from Europe, Oxford Institute of Ageing, Oxford, available at: www.ageing.ox.ac.uk/system/files/Working\%20Paper\%20308.pdf

\section{Corresponding author}

Ana João Santos can be contacted at: anajoaocsantos@gmail.com

To purchase reprints of this article please e-mail: reprints@emeraldinsight.com

Or visit our web site for further details: www.emeraldinsight.com/reprints 